\title{
Commentary \\ Effects of mitoTALENs-Directed Double-Strand Breaks on Plant Mitochondrial Genomes
}

\author{
Shin-ichi Arimura (D)
}

Citation: Arimura, S.-i. Effects of mitoTALENs-Directed Double-Strand Breaks on Plant Mitochondrial Genomes. Genes 2021, 12, 153. https://doi.org/10.3390/ genes12020153

Academic Editors: José M. Gualberto and Jean Molinier

Received: 22 December 2020

Accepted: 22 January 2021

Published: 25 January 2021

Publisher's Note: MDPI stays neutral with regard to jurisdictional claims in published maps and institutional affiliations.

Copyright: (C) 2021 by the author. Licensee MDPI, Basel, Switzerland. This article is an open access article distributed under the terms and conditions of the Creative Commons Attribution (CC BY) license (https:// creativecommons.org/licenses/by/ $4.0 /)$.
Graduate School of Agricultural and Life Sciences, The University of Tokyo, Tokyo 113-8657, Japan; arimura@g.ecc.u-tokyo.ac.jp; Tel.: +81-70-3284-6496

\begin{abstract}
Mitochondrial genomes in flowering plants differ from those in animals and yeasts in several ways, including having large and variable sizes, circular, linear and branched structures, long repeat sequences that participate in homologous recombinations, and variable genes orders, even within a species. Understanding these differences has been hampered by a lack of genetic methods for transforming plant mitochondrial genomes. We recently succeeded in disrupting targeted genes in mitochondrial genomes by mitochondria-targeted transcription activator-like effector nucleases (mitoTALENs) in rice, rapeseed, and Arabidopsis. Double-strand breaks created by mitoTALENs were repaired not by non-homologous end-joining (NHEJ) but by homologous recombination (HR) between repeats near and far from the target sites, resulting in new genomic structures with large deletions and different configurations. On the other hand, in mammals, TALENs-induced DSBs cause small insertions or deletions in nuclear genomes and degradation of mitochondrial genomes. These results suggest that the mitochondrial and nuclear genomes of plants and mammals have distinct mechanisms for responding to naturally occurring DSBs. The different responses appear to be well suited to differences in size and copy numbers of each genome.
\end{abstract}

Keywords: plant mitochondrial genome; mitoTALENs; genome editing

Mitochondria, in addition to generating cellular energy in the form of ATP through oxidative phosphorylation, also produce reactive oxygen species that cause double-strand breaks (DSBs) in the mitochondrial DNA. DSBs in mitochondrial DNAs can also be created by replication errors [1,2]. DSBs of DNA can be severely damaging, so organisms have developed mechanisms for repairing them. Such mechanisms have also been studied extensively in plant mitochondria [3-5]. DSBs are mainly repaired by two mechanisms, homologous recombination (HR) and non-homologous end joining (NHEJ). HR is a high-fidelity repair system that uses an intact copy of the sequence as a repair template, while NHEJ attaches the ends of DSBs, without using templates, and can result in small insertions or deletions (In/Dels) at the repaired sites.

\section{Repair Pathways for Naturally Occurring DNA Double-Strand Breaks}

In the nuclei of plants and mammals, NHEJ is a major pathway for DSB repair (although it is not a major pathway in meiosis and HR is major even in somatic cells in the moss Physcomitrella patens). NHEJ is well-suited for the nucleus because it does not need repair templates, which are rarely available in the nucleus (Figure 1c). Nuclear genomes have a copy of the correct template in the sister chromatid, but the sister chromatid is so large (about $30 \mathrm{Mb}$ in Arabidopsis), the template is difficult to find. Instead, prompt end-joining after DSBs seems to be essential in the nucleus, even though it occasionally causes small errors at the repair sites. That is because one of the DNA fragments created by a DSB will not have a centromere, which is needed to pull the fragment (and its many genes) into the daughter cells during mitosis.

DNA repair mechanisms of mitochondria are different from those in the nucleus, and they are also different between plants and mammals. The mitochondrial DNAs (mtDNA) of mammals are circular molecules with sizes of about $16 \mathrm{~kb}$. They can be isolated from 
some mammalian cultured cells with miniprep kits [6]. The mutation rate of mammalian mtDNA is more than 10 times faster than it is in the nucleus $[7,8]$, but the gene order (synteny) is well conserved in diverse species. For example, the gene order is the same in humans and zebrafish, which diverged about 0.4 billion years ago. In contrast, the mitochondrial genomes of flowering plants (angiosperms) have variable gene orders, variable sizes, and a slower mutation rate (about 10 times slower than that in the nucleus) $[9,10]$. These differences suggest that mitochondrial DNA repair mechanisms are also different in mammals and plants. In mammalian mtDNAs, linear DNAs generated by DSBs seem to be promptly degraded rather than repaired [11-13]. Degrading seems safer than repairing because it is less likely to introduce mutations and because mammalian cells have high (>1000) copy numbers of mtDNAs [14], which makes repair unnecessary.

The mitochondrial genomes of angiosperms are generally much larger than those in mammals. They usually range from $200 \mathrm{~kb}$ to $500 \mathrm{~kb}$ [10], but can be as low as $70 \mathrm{~kb}$ [15] and as high as $12 \mathrm{Mb}$ [16]. Plant mitochondrial genomes are mainly detected as linear molecules, but they can also exist in branched forms and in the form of a small number of circular molecules [17-20]. However, assembled mtDNAs are usually represented as a small number of circular molecules. Arabidopsis cells each have about 300-500 mitochondria, but only about 50-100 mtDNA copies [21], resulting in a shortage of genomic information in most mitochondria. The shortage is compensated for by constant fission and fusion of mitochondria [22-25]. In the mitochondrial genomes of flowering plants, homologous recombinations (HRs) occur between large identical repeats, resulting in alternative configurations of the genome that are referred to as multi-partite structures [26-28]. Large repeats $(>500 \mathrm{bp}$ ) are more identical and more active in HR than intermediate repeats $(500 \mathrm{bp}>50 \mathrm{bp}$ ) and small repeats $(<50 \mathrm{bp})[5,10]$. If a DSB naturally occurs in a plant mtDNA, HR seems to be a reliable and reasonable repair method because the DSB ends can easily find template sequences in the mitochondrial genome due to its many copies in each cell and tiny size compared to the nuclear genome (1/300 the size in Arabidopsis). They imply that in plants, mtDNA is sufficiently abundant for a repair template to be easily found, but not enough for degradation to be a safe solution.

(a)

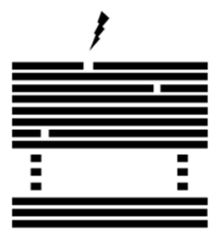

Short (16kb) and copious (>1000/cell) $\rightarrow$ Degradation of DNA with DSBs (b)

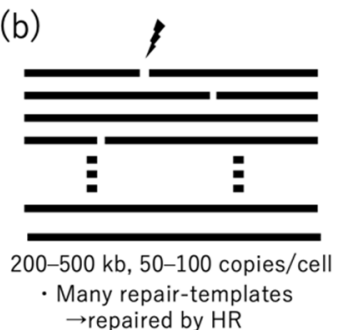

,

(c)

Centromere

- Very long ( $25 \mathrm{Mb} /$ chromosome) and only 2 copies/cell.

- Very difficult to find a single locus of the repair-template for HR

- A DNA string without centromere will be lacked in the progenies.

$\rightarrow \mathrm{NHEJ}$ is (error-prone but) a better way to maintain genome than HR.

Figure 1. Comparison of double-strand breaks in mitochondrial and nuclear genomes. (a) Mammalian mitochondria, (b) plant mitochondria, and (c) mammalian and plant nuclei.

\section{2. mitoTALENs-Directed DSBs in Mammalian and Plant Mitochondrial DNAs}

Different sequence-specific nucleases, including CRISPR/Cas9, transcription activatorlike effector nucleases (TALENs), and zinc finger nucleases (ZFNs), are frequently used to disrupt targeted sites in nuclear genomes [29-31]. The CRISPR/Cas9 system is used in most nuclear genome editing [31,32], but it doesn't work well with mitochondrial genomes because it is difficult to transport the guide RNAs that CRISPR/Cas9 uses into the mitochondria [33]. On the other hand, TALENs recognize DNA sequences through an assembly of protein components, and thus TALENs can be easily and effectively transported into mitochondria by merely attaching a mitochondrial pre-sequence to their $\mathrm{N}$-terminus. 
Therefore, TALENs are now mainly used for creating DSBs at specific sites in mitochondria (Figure 2). TALENs are usually used as a pair, with each molecule recognizing 10-20 bp sequences before and after a 10-20 bp target sequence. Each molecule, in addition to its recognition domain, has a FokI nuclease. After a sequence is recognized, the FokI domains of the paired molecules dimerize and cut out the targeted sequence.

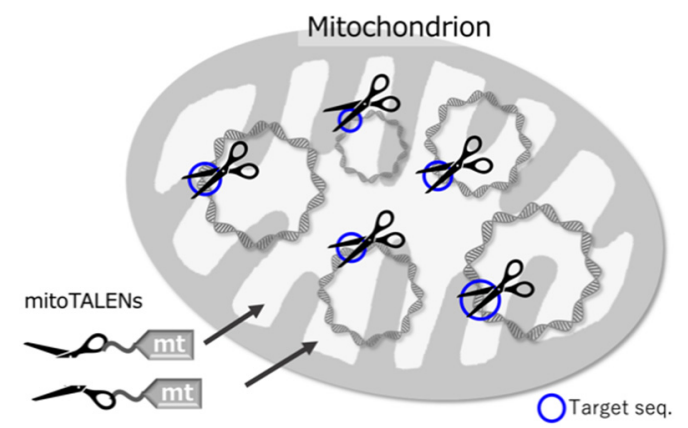

Figure 2. Schematic drawing of mitoTALENs in a mitochondrion. The mitoTALENs are introduced by a mitochondrial targeting sequence $(\mathrm{mt})$, which is cleaved on entry. Each mitoTALEN can be represented as one scissor blade. When joined at the target site, they form a functional scissor-like nuclease.

mitoTALENs, i.e., TALENs with mitochondrial targeting peptides (Figure 2), were first used in mammalian cultured cells [34] and then in mice [35]. In these and other cases, the targeted sequences were located in heteroplasmic mitochondrial DNAs. Heteroplasmy refers to the presence of two or more kinds of mitochondrial DNAs in a cell, which may have different SNPs or In/Dels. Heteroplasmy is observed in healthy mammalian cells and can also increase in an age-dependent manner [8]. Some mitochondrial diseases are characterized by heteroplasmy that occurs as a result of harmful mutations. When the ratio of mutated DNAs rises above a threshold (60-90\%), defects in respiration and other symptoms can occur $[8,36,37]$. Decreasing the ratio of mutated mtDNAs is thought to heal the mitochondrial diseases. In these cases, mitoTALENs can be useful as they could target and destroy the mutated DNAs. This has been demonstrated in cultured cells from humans and mice with pathogenic mtDNA mutations. mtDNAs with the target sequences were specifically decreased (Figure 3a), and respiration-defective cells were rescued (reviewed in [8]). In mammalian cells, mtDNAs with DSBs are quickly degraded rather than repaired [13]. The degradation is carried out mainly by the exonuclease activity of DNA polymerase $\gamma[11,12]$.

We recently made plant expression vectors for pairs of mitoTALENs on Ti-plasmids and introduced them into the nuclei of BT-type cytoplasmic male sterility (CMS) rice and Kosena-type CMS rapeseed [38]. We targeted two genes (orf-79 and orf-125) that were thought to be responsible for CMS in these plants. CMS is an agriculturally important trait; CMS varieties are useful because they can produce F1 hybrid seeds easily and efficiently. In both rice and rapeseed, many of the transformants had large (several hundred bp to several $\mathrm{kb}$ ) deletions in their mitochondrial genomes that included the target genes. The ends of the remaining sequences were connected not to each other's ends but to sequences at distant loci (Figure 3b). The connections occurred through repeats that ranged in size from 10 to 1000 bases and that had identities as low as $90 \%$. The recombinations altered the configuration of the genome by introducing or deleting repeats and changing the gene order. We also used mitoTALENs to knock out two redundant mitochondrial genes (atp6-1 and atp6-2) in Arabidopsis, which resulted in similar alterations of the genome [39]. Homologous recombinations usually faithfully repair DSBs by using templates. However, repeated attacks of mitoTALENs on the target site might create a shortage of templates, resulting in recombinations via intermediate and short repeats. Such ectopic recombinations are usually suppressed by factors like MSH1 and other repair mechanisms [4,5]. Several lines of rice, rapeseed, and Arabidopsis were generated by transformation with mitoTALENs. 
The same repaired genome structures were detected in each of the lines, indicating that the mitochondrial genomes of each plant were in homoplasmic states.

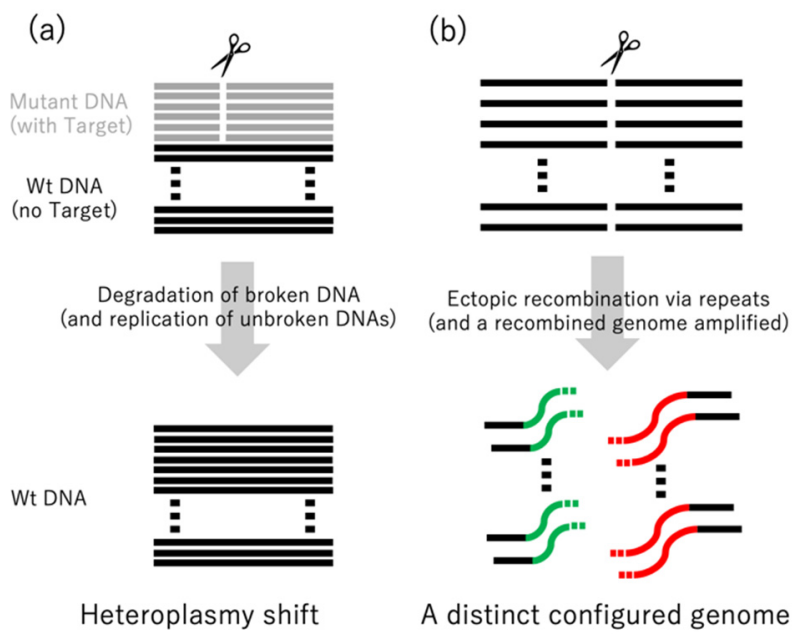

Figure 3. Comparison of the effects of mitoTALENs in mammalian and plant mitochondria. In mammals (a), mitoTALENs create DSBs at different sites of mutation, resulting in selective elimination of the mutant DNAs (resulting in a shift from heteroplasmy to homoplasmy). In plants (b), all copies of the specific sites are cut, resulting in different conformations of the genome by recombinations between repeats near and far from the target sites.

The above studies demonstrate how sequence-specific nucleases bring about different outcomes in the mitochondrial and nuclear genomes of plants and mammals. The difference in the outcomes can be attributed to distinct repair mechanisms that are specifically adapted to each genome.

Funding: This research was partly supported by grants from the Takeda Science Foundation, the Univ. of Tokyo GAP fund program, and partly from the Japan Society for the Promotion of Science (Grant Numbers, 20H00417, 19H02927, and 19KK0391).

Institutional Review Board Statement: Not applicable.

Informed Consent Statement: Not applicable.

Data Availability Statement: Not applicable.

Acknowledgments: I thank many graduate students and staff members in the Plant Molecular Genetics Laboratory at the University of Tokyo for their support of our mitochondrial research over the years.

Conflicts of Interest: The authors declare no conflict of interest.

\section{References}

1. Alexeyev, M.; Shokolenko, I.; Wilson, G.; LeDoux, S. The maintenance of mitochondrial DNA integrity-Critical analysis and update. Cold Spring Harb. Perspect. Biol. 2013, 5, a012641. [CrossRef] [PubMed]

2. Copeland, W.C.; Longley, M.J. Mitochondrial genome maintenance in health and disease. DNA Repair 2014, 19, 190-198. [CrossRef] [PubMed]

3. Christensen, A.C. Mitochondrial DNA repair and genome evolution. Annu. Plant Rev. Online 2018, 50, 11-32.

4. Chevigny, N.; Shatz-Daas, D.; Lotfi, F.; Gualberto, J.M. DNA Repair and the Stability of the Plant Mitochondrial Genome. Int. J. Mol. Sci. 2020, 21, 328. [CrossRef] [PubMed]

5. Gualberto, J.M.; Newton, K.J. Plant Mitochondrial Genomes: Dynamics and Mechanisms of Mutation. Annu. Rev. Plant Boil. 2017, 68, 225-252. [CrossRef] [PubMed]

6. Quispe-Tintaya, W.; White, R.R.; Popov, V.N.; Vijg, J.; Maslov, A.Y. Fast mitochondrial DNA isolation from mammalian cells for next-generation sequencing. Biotechniques 2013, 55, 133-136. [CrossRef]

7. Wallace, D.C.; Ye, J.H.; Neckelmann, S.N.; Singh, G.; Webster, K.A.; Greenberg, B.D. Sequence-Analysis of Cdnas for the Human and Bovine Atp Synthase $\beta$-Subunit-Mitochondrial-DNA Genes Sustain 17 Times More Mutations. Curr. Genet. 1987, 12, 81-90. [CrossRef] [PubMed] 
8. Nissanka, N.; Moraes, C.T. Mitochondrial DNA heteroplasmy in disease and targeted nuclease-based therapeutic approaches. EMBO Rep. 2020, 21, e49612. [CrossRef]

9. Mower, J.P.; Touzet, P.; Gummow, J.S.; Delph, L.F.; Palmer, J.D. Extensive variation in synonymous substitution rates in mitochondrial genes of seed plants. BMC Evol. Biol. 2007, 7, 135. [CrossRef]

10. Kubo, T.; Newton, K.J. Angiosperm mitochondrial genomes and mutations. Mitochondrion 2008, 8, 5-14. [CrossRef]

11. Nissanka, N.; Bacman, S.R.; Plastini, M.J.; Moraes, C.T. The mitochondrial DNA polymerase $\gamma$ degrades linear DNA fragments precluding the formation of deletions. Nat. Commun. 2018, 9, 2491. [CrossRef] [PubMed]

12. Peeva, V.; Blei, D.; Trombly, G.; Corsi, S.; Szukszto, M.J.; Rebelo-Guiomar, P.; Gammage, P.A.; Kudin, A.P.; Becker, C.; Altmuller, J.; et al. Linear mitochondrial DNA is rapidly degraded by components of the replication machinery. Nat. Commun. 2018, 9, 1727. [CrossRef]

13. Bayona-Bafaluy, M.P.; Blits, B.; Battersby, B.J.; Shoubridge, E.A.; Moraes, C.T. Rapid directional shift of mitochondrial DNA heteroplasmy in animal tissues by a mitochondrially targeted restriction endonuclease. Proc. Natl. Acad. Sci. USA 2005, 102, 14392-14397. [CrossRef] [PubMed]

14. Wiesner, R.J.; Ruegg, J.C.; Morano, I. Counting target molecules by exponential polymerase chain reaction: Copy number of mitochondrial DNA in rat tissues. Biochem. Biophys. Res. Commun. 1992, 183, 553-559. [CrossRef]

15. Skippington, E.; Barkman, T.J.; Rice, D.W.; Palmer, J.D. Miniaturized mitogenome of the parasitic plant Viscum scurruloideum is extremely divergent and dynamic and has lost all nad genes. Proc. Natl. Acad. Sci. USA 2015, 112, E3515-E3524. [CrossRef] [PubMed]

16. Sloan, D.B.; Alverson, A.J.; Chuckalovcak, J.P.; Wu, M.; McCauley, D.E.; Palmer, J.D.; Taylor, D.R. Rapid evolution of enormous, multichromosomal genomes in flowering plant mitochondria with exceptionally high mutation rates. PLoS Biol. 2012, 10, e1001241. [CrossRef] [PubMed]

17. Sloan, D.B. One ring to rule them all? Genome sequencing provides new insights into the 'master circle' model of plant mitochondrial DNA structure. New Phytol. 2013, 200, 978-985. [CrossRef]

18. Bendich, A.J. Reaching for the ring: The study of mitochondrial genome structure. Curr. Genet. 1993, 24, 279-290. [CrossRef] [PubMed]

19. Oldenburg, D.J.; Bendich, A.J. DNA maintenance in plastids and mitochondria of plants. Front. Plant Sci. 2015, 6, 883. [CrossRef]

20. Cheng, N.; Lo, Y.S.; Ansari, M.I.; Ho, K.C.; Jeng, S.T.; Lin, N.S.; Dai, H. Correlation between mtDNA complexity and mtDNA replication mode in developing cotyledon mitochondria during mung bean seed germination. New Phytol. 2017, 213, 739-751. [CrossRef]

21. Preuten, T.; Cincu, E.; Fuchs, J.; Zoschke, R.; Liere, K.; Börner, T. Fewer genes than organelles: Extremely low and variable gene copy numbers in mitochondria of somatic plant cells. Plant J. 2010, 64, 948-959. [CrossRef] [PubMed]

22. Arimura, S.; Yamamoto, J.; Aida, G.P.; Nakazono, M.; Tsutsumi, N. Frequent fusion and fission of plant mitochondria with unequal nucleoid distribution. Proc. Natl. Acad. Sci. USA 2004, 101, 7805-7808. [CrossRef]

23. Arimura, S. Fission and Fusion of Plant Mitochondria, and Genome Maintenance. Plant Physiol. 2018, 176, 152-161. [CrossRef]

24. Logan, D. The dynamic chondriome. Annu. Plant Rev. Online 2017, 50, 67-109.

25. Paszkiewicz, G.; Gualberto, J.M.; Benamar, A.; Macherel, D.; Logan, D.C. Arabidopsis Seed Mitochondria Are Bioenergetically Active Immediately upon Imbibition and Specialize via Biogenesis in Preparation for Autotrophic Growth. Plant Cell 2017, 29, 109-128. [CrossRef] [PubMed]

26. Small, I.; Suffolk, R.; Leaver, C.J. Evolution of plant mitochondrial genomes via substoichiometric intermediates. Cell 1989, 58, 69-76. [CrossRef]

27. Palmer, J.D.; Shields, C.R. Tripartite Structure of the Brassica-Campestris Mitochondrial Genome. Nature 1984, 307, 437-440. [CrossRef]

28. Schardl, C.L.; Pring, D.R.; Lonsdale, D.M. Mitochondrial DNA rearrangements associated with fertile revertants of S-type male-sterile maize. Cell 1985, 43, 361-368. [CrossRef]

29. Voytas, D.F. Plant genome engineering with sequence-specific nucleases. Annu. Rev. Plant Biol. 2013, 64, 327-350. [CrossRef]

30. Osakabe, Y.; Osakabe, K. Genome editing with engineered nucleases in plants. Plant Cell Physiol. 2015, 56, 389-400. [CrossRef]

31. Zhu, H.; Li, C.; Gao, C. Applications of CRISPR-Cas in agriculture and plant biotechnology. Nat. Rev. Mol. Cell Biol. 2020, 21, 661-677. [CrossRef] [PubMed]

32. Chen, K.; Wang, Y.; Zhang, R.; Zhang, H.; Gao, C. CRISPR/Cas Genome Editing and Precision Plant Breeding in Agriculture. Annu. Rev. Plant Boil. 2019, 70, 667-697. [CrossRef] [PubMed]

33. Gammage, P.A.; Moraes, C.T.; Minczuk, M. Mitochondrial Genome Engineering: The Revolution May Not Be CRISPR-Ized. Trends Genet. 2017, 34, 101-110. [CrossRef] [PubMed]

34. Bacman, S.R.; Williams, S.L.; Pinto, M.; Peralta, S.; Moraes, C.T. Specific elimination of mutant mitochondrial genomes in patient-derived cells by mitoTALENs. Nat. Med. 2013, 19, 1111-1113. [CrossRef]

35. Reddy, P.; Ocampo, A.; Suzuki, K.; Luo, J.; Bacman, S.R.; Williams, S.L.; Sugawara, A.; Okamura, D.; Tsunekawa, Y.; Wu, J.; et al. Selective elimination of mitochondrial mutations in the germline by genome editing. Cell 2015, 161, 459-469. [CrossRef] [PubMed] 
36. Nakada, K.; Inoue, K.; Ono, T.; Isobe, K.; Ogura, A.; Goto, Y.I.; Nonaka, I.; Hayashi, J.I. Inter-mitochondrial complementation: Mitochondria-specific system preventing mice from expression of disease phenotypes by mutant mtDNA. Nat. Med. 2001, 7, 934-940. [CrossRef]

37. Ono, T.; Isobe, K.; Nakada, K.; Hayashi, J.I. Human cells are protected from mitochondrial dysfunction by complementation of DNA products in fused mitochondria. Nat. Genet. 2001, 28, 272-275. [CrossRef]

38. Kazama, T.; Okuno, M.; Watari, Y.; Yanase, S.; Koizuka, C.; Tsuruta, Y.; Sugaya, H.; Toyoda, A.; Itoh, T.; Tsutsumi, N.; et al. Curing cytoplasmic male sterility via TALEN-mediated mitochondrial genome editing. Nat. Plants 2019, 5, 722-730. [CrossRef]

39. Arimura, S.; Ayabe, H.; Sugaya, H.; Okuno, M.; Tamura, Y.; Tsuruta, Y.; Watari, Y.; Yanase, S.; Yamauchi, T.; Itoh, T.; et al. Targeted gene disruption of ATP synthases 6-1 and 6-2 in the mitochondrial genome of Arabidopsis thaliana by mitoTALENs. Plant J. 2020. [CrossRef] 